Nr $257 \bullet 1996$

Young novice drivers: Towards a model of their accident involvement

Nils Petter Gregersen, VTI and Per Bjurulf, University of Linköping

Reprint from Accident Analysis \& Prevention, Vol. 28, No. 2, pp. 229-241, 1996

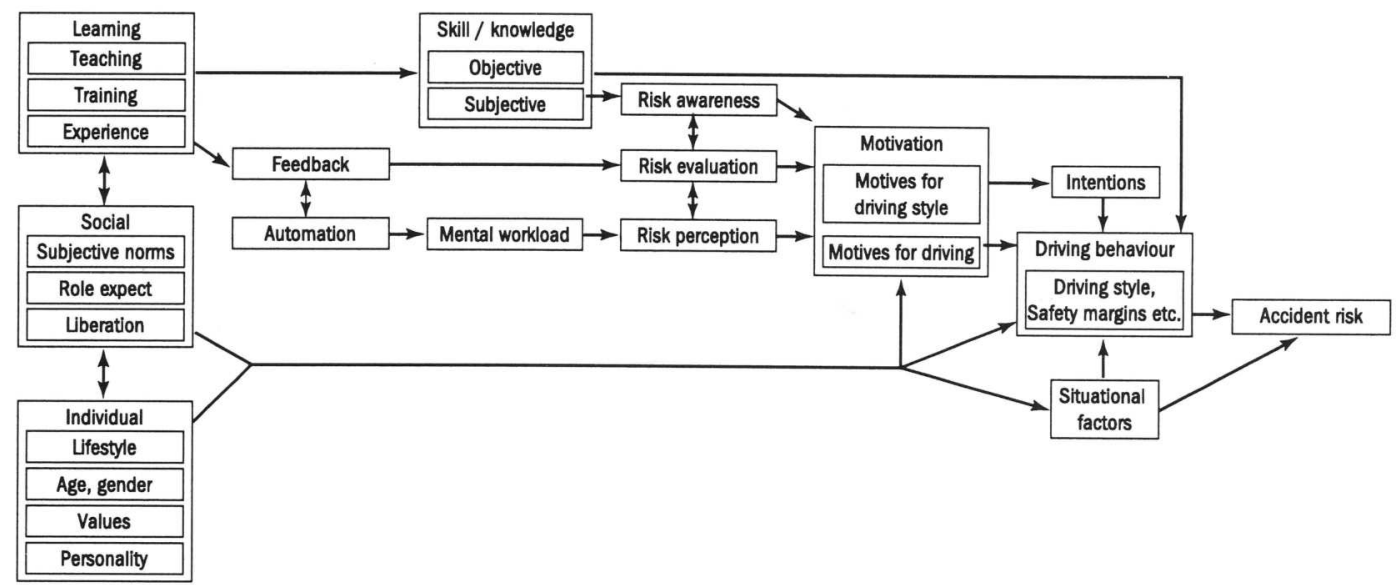





\section{V

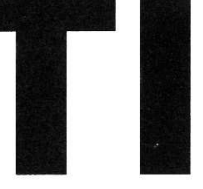 \\ särtryck}

Nr $257 \bullet 1996$

Young novice drivers: Towards a model of their accident involvement

Nils Petter Gregersen, VTI and

Per Bjurulf, University of Linköping, Sweden

Reprint from Accident Analysis \& Prevention, Vol. 28, No. 2, pp. 229-241, 1996 
Samhall Brahe AB, Grafiska Linköping 1996 


\title{
YOUNG NOVICE DRIVERS: TOWARDS A MODEL OF THEIR ACCIDENT INVOLVEMENT
}

\author{
Nils Petter Gregersen ${ }^{1,2}$ and Per Bjurulf
}

\author{
${ }^{1}$ Swedish Road and Transport Research Institute (VTI), S-581 95 Linköping, Sweden and ${ }^{2}$ Department of \\ Community Medicine, University of Linköping, Sweden
}

(Accepted 20 August 1995)

\begin{abstract}
There are two main purposes of this article. The first is to present a model of young drivers' accident involvement, including the most important processes in the development of their driving behaviour. The model describes the relations between the learning process, the individual preconditions and the social influence and how these are related to driving behaviour and accident involvement through different processes such as skill acquisition, self assessment, information processing, feedback and motivation. The second purpose is to present a state-of-the-art report for the different aspects of the model by referring to some of the literature on young drivers.
\end{abstract}

Keywords - Recently qualified drivers, Safety, Driver training

\section{INTRODUCTION}

Extensive research has been carried out to find out why young drivers behave the way they do. The development of theories and driver models have, however, not advanced so far that it is possible to draw reliable conclusions about causes. Without detailed knowledge, it is impossible to make reliable decisions about suitable measures.

Much traffic safety work is carried out on the basis of common sense, which is often found inadequate in reducing the high accident involvement among young novice drivers.

Research in this area has produced or applied several theories and empirical findings, pointing out a number of interesting aspects relevant for the behaviour of young drivers.

The purpose of this article is to present a model of young driver behaviour and accident involvement. The model is based on current knowledge about young drivers' accident involvement which also includes several existing general as well as applied theories. The aim of presenting such a model is to suggest a structure for the relations between different behaviour and accident influencing processes among young drivers. The model is presented in Fig. 1 and will also function as a disposition for this article. The following section describing the details of the model is devided in two subsections, one about the learning process and one about the individual preconditions and the social influence.

A common aspect of many theories relevant for young driver behaviour is that the empirical support is weak. Often, use is made of a posteriori hypotheses or theories translated from other areas without being subjected to sufficient applied experimental testing. A typical example is the importance of subjective skill, see Fig. 1. This tells us something about the problem of overestimation, which fulfils a purpose by providing a possible explanation of why we often fail to prove effects of measures such as further education of drivers. Several questionnaire studies, described below, have also shown how young drivers overestimate their capacity, but the number of experiments testing the idea of overestimation effects are few.

The same reasoning applies to the importance of driving skill. Traditionally, in practical road safety work, insufficient skill has been regarded as one of the most important reasons for young drivers' accident involvement. This is why great efforts have been made to increase traffic education in schools, with the focus on providing rules for different road user categories. Today we believe, however, that skill, traditionally defined, is only a limited part of a rather complex structure of factors as shown in Fig. 1.

Figure 1 also mentions automation and mental workload. The general level of knowledge about this area is high, but the experimental testing of the viability of these theories in regard to the problems of young drivers is limited and contradictory.

It is also obvious that few efforts have been made to treat these different factors as an interactive complex. This aspect is important, since it is only with 


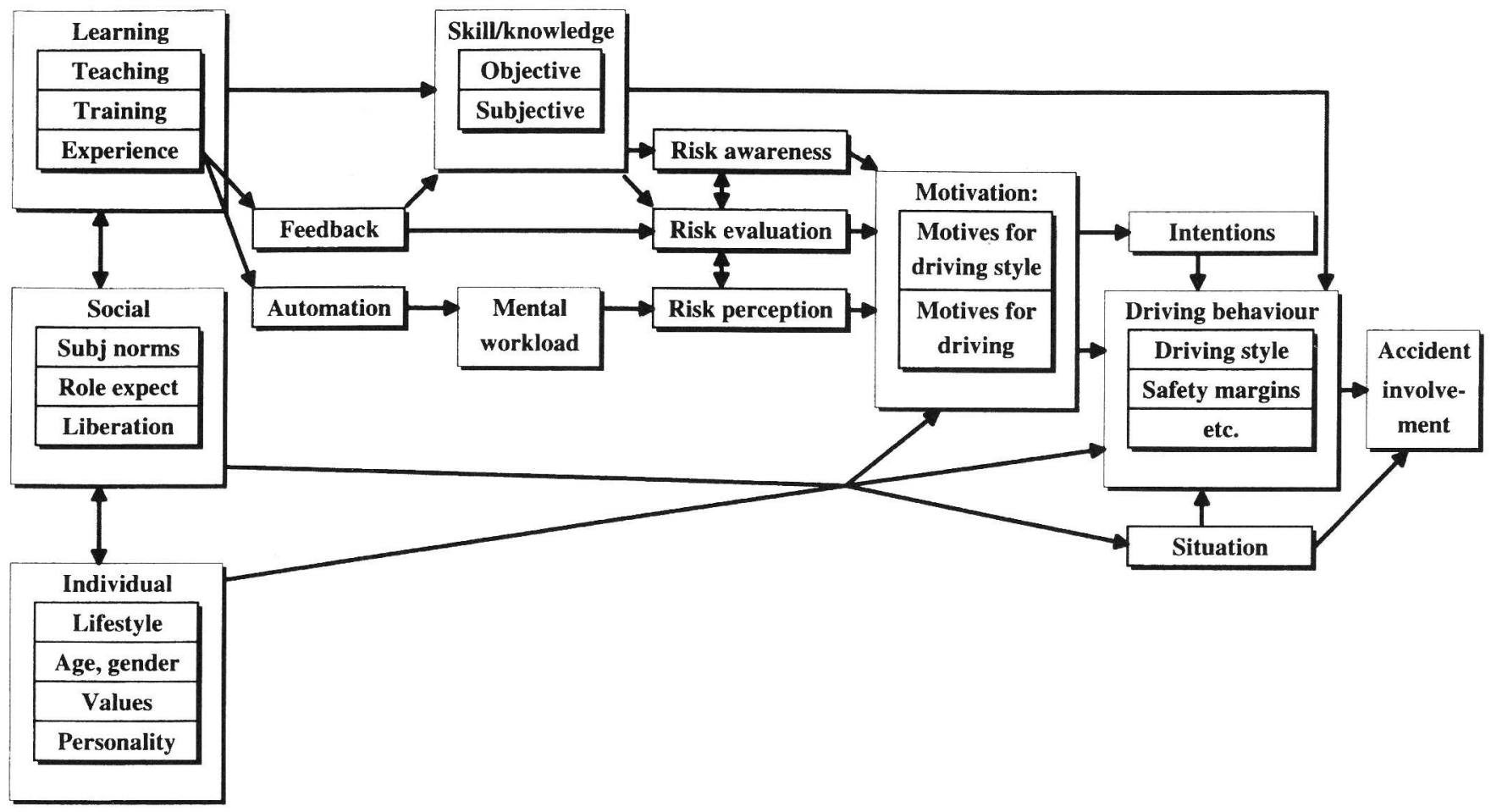

Fig. 1. Model of young driver's accident involvement.

such knowledge we can study their relative importance and make priorities about countermeasures.

In the following, the various components of the suggested model on young drivers' accident involvement (Fig. 1) will be discussed in more detail, including an attempt at describing the state of the art of the different aspects of the model.

\section{THE LEARNING PROCESS}

According to our model, the learning process consists of three main branches. One refers to the initial learning process when becoming a driver and obtaining a driver's licence. The other two are more related to the long term experience where the feedback from the traffic is important for the risk evaluation and thus influences the motivational aspects of driving. The experience is also important for the skill acquisition process where behaviour patterns are automated and the mental workload during the novice period is reduced. Each of these three parts of the learning process will be discussed below.

\section{The initial driver training}

In applied practical driver training the focus is directed towards the first process, the period of becoming a driver and obtaining a licence. This period is traditionally short, even if there are examples to the contrary, and certainly many learner drivers try to minimize it as much as possible and to obtain the licence as soon as possible.

Much of the development of the learning process of the driver has focused on this initial period, trying to decide what the best training strategy is. There are several studies on these educational strategies showing for example that drivers who learn without professional teaching do not have a higher accident risk than drivers who learn from traffic schools (Gregersen 1994; Potvin et al. 1988; Jones 1973; Shaoul 1975; Strang et al. 1982; Stock et al. 1984; Skelly 1968; Levy 1988, 1990). English studies on passing rates show that the more professional training, the lower passing rate and the more private training, the higher passing rate (Forsythe 1992). According to Swedish statistics on passing rates, privately educated drivers have a lower passing rate in the test than those who are educated in professional driving schools (Swedish National Road Administration).

Another conclusion from research into knowledge and skill in driving is that many evaluations of efforts to make the teaching process more efficient have failed to prove any effects on safety. This has been the case in the use of driving ranges for basic driving ability (Strang et al. 1982; Brazell 1962; Dreyer and Janke 1979), in skid training (Glad 1988; Eriksson 1983) and in the use of driving simulators (Shaoul 1975; Jones 1973). These evaluations are, however, rather old and there has been a rapid development 
of possibilities for new educational methods and strategies e.g. by using computers, new types of simulators and interactive video. However, scientifically evaluated experience of such methods continues to be rather limited.

What we do not know is how level of knowledge influences the accident risk in itself. A natural assumption is that a basic level of knowledge is needed to be able to drive well and safely and that a higher level of skill leads to better driving ability. It is, however, not very obvious how we can use this to determine whether skill and knowledge influence accident risk. Are there any threshold effects where extra knowledge adds only marginal gains? So far, these questions have not been adequately answered.

The need for knowledge and skill is also an example of the necessity of including the whole problem complex. Knowledge and skill are necessary to be able to drive. Through the years, the process of teaching has been developed continuously through better textbooks and teaching aids, improved teaching methods, curricula etc. Seen in the light of all the other psychological and social aspects in the model (Fig. 1) it may be adequate to assume that there are also other aspects where the potential for reducing accident involvement may be much larger. It is, however, important not to neglect the problem of poor knowledge and skill. As soon as there are gaps in the driver's knowledge, there may be potential risks involved in his driving. There are several ways of identifying a lack of knowledge. One way is to analyse the percentage of incorrect answers in the theoretical part of the driving test. In an investigation among drivers in Ontario (Matsui et al. 1991) several gaps in knowledge were revealed. In some respects, young drivers were more likely to have inadequate knowledge than drivers in general. In other aspects, however, knowledge among young drivers was better.

In the model (Fig. 1) it is assumed that the level of knowledge and skill may influence driving behaviour directly. It is obvious that there is a direct relation between skill level and manoeuvring behaviour, but there is also a relation between lack of knowledge/skill and erroneous behaviour. It is also obvious that these errors are not performed consciously. If the driver does not know that a behaviour is wrong, the error may be described as unconscious. In that case, the unconscious errors also lead to higher risk exposure without knowing about it. However, as yet it is impossible to estimate the size of this problem.

Skill acquisition is also dependent on the kind of experience a driver achieves. The learning process is not limited to the initial period when the licence is obtained. The major importance of experience on reduction of accident involvement has been shown in a large number of studies and several general learning theories include experience as an important ingredient. This influence of experience will be discussed below.

\section{Learning through experience}

Experience is of major importance for the initial accident reduction among drivers, as shown by a number of studies. It has been found that drivers with a higher mileage per year have fewer accidents/mileage (Spolander 1983a; Pelz and Schuman 1971). The findings are also supported by various studies comparing the influence of age and experience. One example is the results of Maycock et al. (1991) who studied a large number of novice drivers of different ages, where it was found that accident involvement in all age groups is initially high and decreases during the first few years. The initial level of risk is, however, reduced with higher licensing age, showing that other, age-influenced aspects are also of importance (Fig. 2). Maycock et al. found that the initial risk during the first few years decreased by $59 \%$ due to experience and $31 \%$ due to age factors. The Maycock figure also shows that age-factors are more important at younger ages.

Similar results have also been shown in a Canadian examination of the crash involvement rates of novice drivers aged 16-55 (Cooper et al. 1995). All age groups of novice drivers had a higher initial involvement in culpable accidents. The youngest novice drivers, 16 years old, were found to have the highest initial accident involvement.

If the same kind of analysis is carried out on even younger drivers, the age factor seems to become dominant. In an American study, it has been shown that 15 year old drivers have a much higher novice driver risk than 17 year old beginners (Levy 1990). The contributing effect of age has also been shown in Canada, where Gaudry (1987) concluded that their change in licensing age in 1962 , from 18 to 16 years increased accident involvement among new drivers by $12 \%$, and fatalities by $24 \%$.

In a study of over 10,000 young drivers, Ferdun et al. (1967) showed that age was of secondary importance next to experience, but that age factors were especially important among young men. Michels and Schneider (1984) concluded from a study on violations among drivers in Geneva that experience is of greater importance than age.

If all these studies are taken into account, it seems that experience as well as age related factors are of vital importance. It also seems clear that experience is of greater importance than age, at least from 17 years of age. The studies showing that age is more important are often American and include drivers of younger ages. Such a conclusion also agrees 


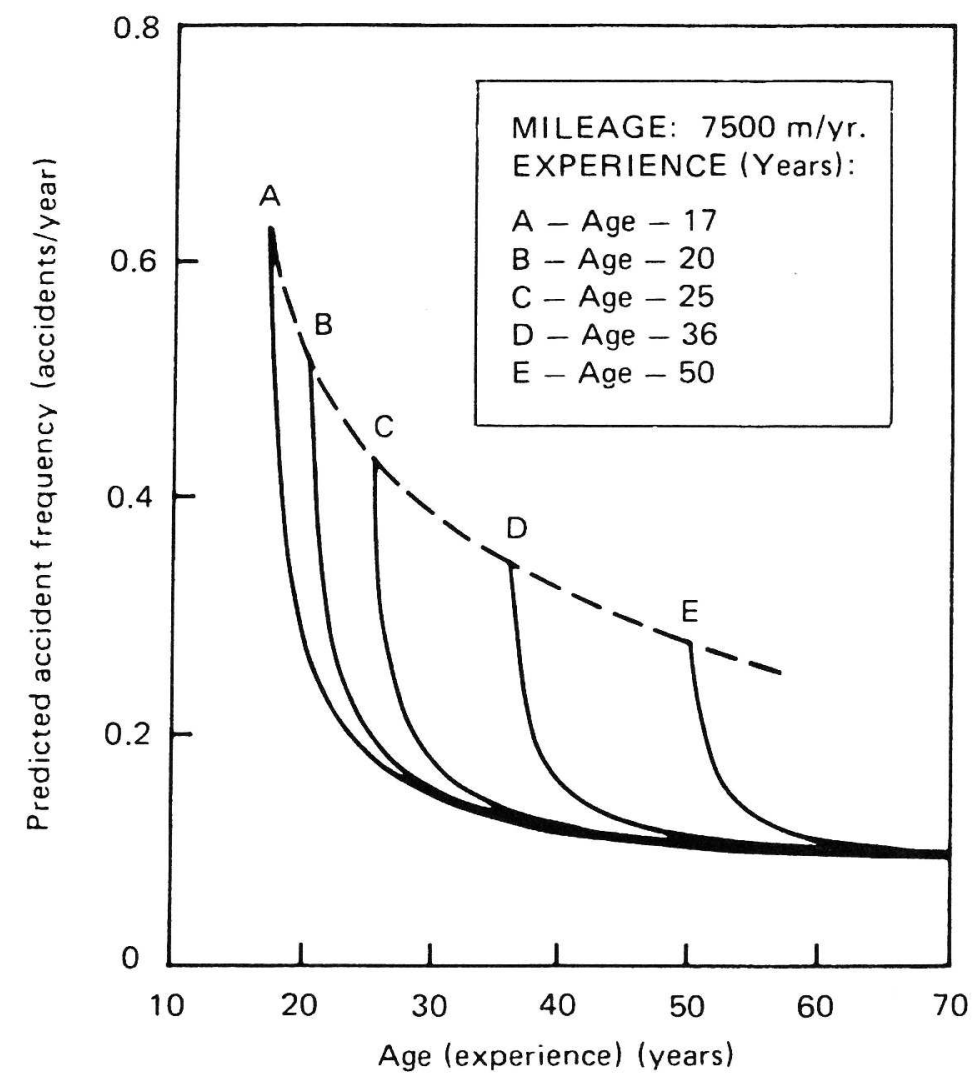

Fig. 2. The influence of age and experience on accident risk (Maycock et al. 1991).

with the trends in the results of Maycock referred to above.

A common model for explaining why experience reduces accident risk states that the novice driver passes through several phases according to how he can handle the large number of tasks involved in driving. The novice driver faces many new situations, all of them demanding cognitive resources. The perceptual situation is new and demands specific patterns of visual search and interpretation of what is happening in the surroundings. The novice driver cannot handle the situation as well as the experienced driver. The car itself also demands cognitive capacity, with a variety of controls, levers and warning devices that must be used and co-ordinated in a complex pattern. The whole traffic environment with its rules and demands on specific behaviour also adds to the demands on cognitive resources.

With time, however, more and more of these tasks will be automated and the need for free cognitive resources will be reduced. This assumption has support, not only in findings concerning visual search patterns (Mourant and Rockwell 1972) but also in studies of prolonged reaction time (Quimby and Watts 1981).

The learning process has been described in several general theories with different approaches. Two theories are of special interest for the process of becoming a skilled driver. Anderson (1982) describes in his theory the acquisition of cognitive skill which includes three stages, the declarative stage, the compilation stage and the procedural stage. According to Anderson, knowledge in a new domain always starts out in declarative form and is used interpretively. Through the compilation stage, the system goes from this interpretive application of declarative knowledge to procedures. By building up procedures to perform specific tasks, a great deal of efficiency is achieved both in terms of time and mental capacity, since the interpretive production requires the declarative information to be represented in the working memory, which may be a heavy burden on the working memory capacity.

According to Rasmussen (1984) the development of a skill includes a similar process of automation. In his theory, he describes three levels of human performance: skill-based, rule-based and knowledge-based level. Skill-based behaviour represents sensimotor performance which in its developed form characteristically proceeds without conscious attention or control. Rule-based behaviour consists of compositions of sequences of subroutines that are consciously controlled and goal oriented by a rule that has been 
derived empirically or from other people's knowhow. At the knowledge-based level, explicit goals are formulated and solutions are evaluated through functional reasoning, where the internal structure of the system is explicitly represented by a mental model that may take several different forms. When learning a skill according to Rasmussen, the final stage is the skill level, where automated routines are based on synchronization and optimization of the problem. These behavioural patterns develop while they are controlled and supervised by the higher level activities. During the first phases of skill acquisition, the activity will be controlled by separate cues that are defined individually and related to rules controlling very elementary acts. As skill develops, cues of more global nature will be adopted and rules will be related to activity patterns rather than acts. Finally, the whole task is automated and performed without conscious awareness as long as unexpected deviations do not occur. The higher the skill, the lower the probability of such unexpected deviations. Both Anderson and Rasmussen refer to Fitts (Fitts 1964; Fitts and Posner 1962) who also distinguishes between three phases of learning a skill, in his theory on skill acquisition. These are the cognitive, associative and autonomous phases.

According to these theories, a typical feature of the first stage of learning to drive is the importance of formal rules and the instructions given by the teacher (Brown et al. 1987). As more and more tasks are automated attention will be directed towards interactions with other road users. The behaviour at this stage will still be heavily rule-based. In the final stage, the formal rules and the control skills will become more integrated and the traffic itself will provide more and more guidance for driving behaviour. In this stage, more and more tasks may be carried out simultaneously, since they do not demand so much cognitive capacity.

In a study by Benda and Hoyos (1983), this phenomenon was shown in drivers' risk evaluation of situations in photographs. They found that experienced drivers performed better, compared to less experienced drivers, in integrating moving as well as non-moving objects in their estimation of hazard. A possible alternative explanation of why experienced drivers perform better in complicated situations could be the confounding of age. Korteling $(1990,1992)$ has, however, shown that this is not very probable, since dual task performance as such is better during lower driver ages.

Experienced drivers have been shown in several studies to perceive risk situations quicker than novice drivers (Soliday and Allen 1972; Ahopalo et al. 1987; Quimby and Watts 1981; Finn and Bragg 1986), which supports these theories of automation and mental workload. In the Soliday and Allen study, this pattern was explained by the novice driver's concentration on non-moving objects.

From the safety point of view, one effect of this process is that some skills develop for the better and some for the worse, while some do not develop at all, due to the kind of feedback involved in the acquisition of experience. Duncan et al. (1991) found in a study of novice, normal and expert drivers that the novice drivers were more frequent in mirror checking, they used the brake pedal earlier at intersections and they had a larger following distance when starting overtaking. The normal/expert drivers were better in other scanning behaviour and in car control. This indicates that experience makes the driver better in scanning behaviour and car control, but worse in the other aspects studied.

These theories may be related to general theories of cognitive capacity. The ability to fulfil several tasks simultaneously depends on the quantity and type of "processing resources" that are available or can be allocated. The less resources a task needs, the easier is it to combine it with other tasks. Research has also found that effective time sharing is possible by using different kinds of processing resources. This is described in the "multiple resources theory" (Wickens 1991).

Studies of cognitive load during driving in traffic have shown that the load varies systematically with variations in environment (Harms 1991a,b). The cognitive load was found to be higher in urban areas compared to rural areas. The same study also shows that the driver did not fully compensate for cognitive load by reducing speed. This indicates that drivers also allocate different amounts of cognitive resources in different situations. If so, there is a possible relation to the risk homeostasis theory (Wilde 1982). In situations where the experienced level of risk is small, limited cognitive resources are allocated. The secondary task will use a larger amount of the available resources and the reaction time will be prolonged.

In spite of the fact that many studies have shown or discussed the meaning of cognitive load for driving task, the specific meaning for young novice drivers is unclear. The studies of Mourant and Rockwell (1972) indicate that young drivers' shortcomings in visual searching are caused by high mental workload. In later studies by Miltenburg and Kuiken (1990) an unsuccessful attempt was made to replicate the findings of Mourant and Rockwell. The hypothesis that visual search strategy changed with experience could not be verified.

A large amount of research has been carried out in the general field of visual search, but not so much applied to the driving task. Some results are however presented by Ảberg (1981) showing that there are 
certain processes that are related to experience. $\mathrm{He}$ describes "predictive head movements" which means that the head is moved prior to initializing eye movement, when tracking a target presented in peripheral positions. Mourant and Grimson (1977) found that experienced drivers use more predictive head movements than novice drivers do, which indicates that novice drivers do not use their peripheral sight as effectively as experienced drivers do. Åberg also reviews the literature on the perceptional automation process, which probably is closely related to the automation process of driving behaviour described above. Perceptual automation is explained as a process where repeated experience with stimuli leads to automatic detection. In environments where the stimuli do not change very much, drivers may turn to automized perception and thus lose conscious scanning for critical events, e.g. wild animals. This is in line with his assumption that when the attentional field is directed towards oncoming vehicles, the driver may miss the detection of an animal even when he is looking straight at it. This process was also shown in an experiment by Åberg (1981) where drivers who were instructed to search for moose detected a dummy moose more often than when driving normally without this instruction.

Problems exist in finding ways to increase experience in a safe manner. It is a well known paradox that it is impossible to achieve experience without passing through the initial high risk period. The main question has been whether it is possible to increase experience in some other way. In the main, two strategies have been developed, one being graduated licensing and the other an extended period of practice. Evaluations of graduated licensing systems have been reviewed by Smith (1994). In evaluations of American, Canadian and New Zealand systems, accident reductions between 5 and $16 \%$ were found.

In Norway, an evaluation of a two phase graduated system failed to show the expected accident reducing effect (Glad 1988). Instead, Norway has now changed to a system similar to that in Sweden. The Swedish system has a 2-year practice period between the ages of 16 and 18. The licensing age is 18 years. An evaluation of the Swedish system is being carried out at VTI (Gregersen 1991).

Another potential strategy is to find educational methods for shortening the period necessary to obtain sufficient experience. "Commentary driving" is a typical method of this type, where the driver is expected to improve visual scanning and interpretation (Marek and Sten 1977). However, even if this is a potentially effective strategy, problems may be involved since the mental workload may limit the novice driver's possi- bilities to make full use of its advantages (Gregersen 1994). These aspects need to be investigated further.

The main idea behind the system of a prolonged practice period used in Sweden, Norway, France, Belgium and other countries is to increase experience when driving with an instructor. With 2 years of experience before licensing, a main hypothesis is that the learner will be able to use his cognitive resources better and thus become a safer driver. In Sweden, this new system has also had an effect on other educational strategies. Since the age limit has been lowered, it is now possible for secondary schools to participate in driver education. Many schools have now included driving instruction and practice in their curricula.

In a Norwegian study, 28 learner drivers who were able to practice from 16 years of age were followed during their training period. The age limit for licensing was 18. Their evaluation of the training programme, including several mandatory parts, was positive, but it was shown that they did not make full use of the opportunity to drive and practice. Most of them blamed this on lack of time (Moe 1992).

Many new trends in traffic safety work are related to the way in which we use our cognitive resources. An obvious example is the field of RTI (Road Transport Informatics) with a very rapid development of new techniques which may result in even higher demands on the driver, including multiple task performance and time-sharing (Alm and Nilsson 1990, 1991). For young novice drivers, this may lead to a situation with even more difficulties, which in turn may lead to an even higher accident involvement.

\section{Subjective skill and risk evaluation}

One approach to young drivers and their risk behaviour is to study how they estimate their own ability to handle risky situations. An assumption is that young drivers have a poor knowledge of their ability in this sense. They overestimate their ability. This is a reasonable hypothesis, taking into account normal behaviour among teenagers, especially young men in the middle of their "liberation" process.

In a study by Moe (1986) subjective and objective ability have been compared. He compared an "internal model" of driving ability from a questionnaire study with results from a behavioural study and found a high correspondence between the distributions in the studies. In the second part of his study, he stopped drivers after measuring their speed on a certain road. The results showed that young men in the high speed group believed themselves to be significantly more skilled than the low speed group. This obvious difference was not found among women or older men. 
The significance of overestimation has also been shown in an experiment to determine how different educational strategies influence overestimation (Gregersen 1996). The study was carried out to test the hypothesis that skill oriented training would produce more overestimation than training oriented towards the driver's insight into his own limitations. Two randomly distributed groups of learner drivers were given these two types of training and were asked to estimate their ability in a number of driving tasks. Their estimation was compared with their actual ability and thus the reality of their estimation could be calculated. Drivers in the group with skill training were found to have a significantly higher overestimation of their ability, but no difference was found in observed ability. The conclusion from this study was that driver training ought to be complemented with practical training that makes the driver realize his own limitation. In an experiment in the Swedish Telecom, this strategy for driver training was tested and was found to have a large accident reducing effect compared to the control group (Gregersen et al. 1996).

The most common way of measuring self estimation is by questionnaires. Drivers have been asked to estimate their ability compared to other drivers (Svenson 1981; Spolander 1983a,b; Moe 1984; Finn and Bragg 1986; Matthews and Moran 1986; Gregersen 1993; McGormick et al. 1986). Traditionally, these types of studies show that young drivers consider themselves to be better than other drivers. The pattern has also been shown to be most typical among young men.

Finn and Bragg (1986) found that young drivers estimate their own probability of being involved in an accident as lower than the risk of other young drivers, as well as of other drivers on the whole, in spite of their general estimation that the risk for young drivers is higher. A similar pattern was shown by Matthews and Moran (1986). They also found that young drivers consider themselves more skilled than other drivers, whether young or old.

The conclusion drawn in these studies is that young drivers are poor at estimating their own ability and thus judging risks adequately. They underestimate the risks and overestimate their skill as drivers. It is obvious that there is a relationship between estimated risk and estimated ability. If a driver believes that he is a skilled driver able to handle a dangerous situation, the situation is no longer equally dangerous. From an educational point of view, these findings are complex, since the drivers are not motivated to drive more carefully than they believe is necessary. It also makes matters complicated since a probable outcome may be that drivers reject theoreti- cal information about risks, using explanations such as "It's only a problem for others, not for me as I'm so clever". Several studies have shown that young drivers choose to behave more dangerously (Jonah 1986). They drive faster (Wasielewsky 1984; Wilde 1982; Galin 1981; Koneci et al. 1976; Michels and Schneider 1984; Quimby and Watts 1981). They also drive in ways that increase the probability of conflicts with other drivers. Evans and Wasielewsky (1983) showed that they drive with smaller following distances, which is supported by Lalonde (1979) who showed that young drivers are involved in more rearend collisions. Young drivers also use safety belts less often (Nolén 1988; Lacko and Nilsson 1988; Fhaner and Hane 1973; Evans et al. 1982; Wilson 1984).

Several of these behaviour patterns are combined. It is often the same drivers who drive fast, with small safety margins, more violations, greater alcohol consumption, etc. (Evans et al. 1982; Deutsch et al. 1980; Lawson and Arora 1982; Wilson and Jonah 1985). These findings are additionally supported by the results on correlation between lifestyle and accidents (Gregersen and Berg 1994; Schultze 1990) which are discussed further below. It has also been shown in several studies that young drivers are more influenced by alcohol than others. They are not overrepresented as drunk drivers in traffic but they are overrepresented in accidents where alcohol is involved (Glad 1985; Mayhew et al. 1986; Donovan et al. 1983).

The estimation of oneself as better than others may be a result of two kinds of values, either a "positive self" estimation or a "negative other" estimation. Regarding the possible consequences of the estimation of behaviour, it is important to calculate their proportions.

This has been done in a study by McKenna et al. (1991) where drivers were asked to estimate themselves, as well as the average driver, on separate scales. Since the average driver received an estimation above the middle of the scale, the conclusion was that he was not estimated as poor. The personal estimation was even higher, supporting the common idea that it is probably a matter of "positive self" more than "negative other". In another study McKenna (1993) tested experimentally whether the personal underestimation of probability of encountering negative events was due to illusion of control or unrealistic optimism. $\mathrm{He}$ concluded that there is "clear support for the illusion of control and little support for unrealistic optimism".

When it comes to the relation between motives and driving behaviour, there are two kinds of relevant motives. There are motives for why we drive and motives for how we drive. Both of these influence our driving behaviour. One example of the motives for 
why we drive is that we want to transport something from one point to another. It may, however, also be that we just find satisfaction in driving as such. We drive simply for the purpose of driving. This may be a purely individual motive such as pleasure, relaxation, etc., but it may also be a social motive influenced by subjective norms, role expectations or group pressure. The border between these motives, and those guiding how we drive is indistinct. The motives for how we drive include safety, economy and environmental care. Other examples are showing off, testing limits or competing with other drivers.

The influence of these motives on driving is governed by the reinforcement connected with the behaviour. The relation between motives and reinforcement is quite complicated. Most of us want to drive safely. The problem is to define what this implies in actual behaviour. For the individual driver, it is not so difficult to draw conclusions about driving style. The problem is that an individual easily draws false conclusions. A driving style that is statistically dangerous may not be considered dangerous by the driver as an individual. If a driver exceeds the speed limits, the most probable result will be that he is not stopped by the police, that no accident will happen and that he will arrive at his destination faster. This reinforcement helps him to draw conclusions about individual safe driving that counteract safety in a statistical sense.

The safety motive may be regarded as a "negative" motive. Reinforcement is either neutral or negative. There are never any immediate rewards if a driver tries to drive more safely. As soon as a negative reinforcement fails to appear, the motive may be regarded as satisfied. The absence of accidents is the normal state and thus there are limited possibilities of reducing accident involvement from the individual point of view. The same pattern is valid for the motive of avoiding police checks. As soon as this is avoided, and thereby the punishment, the motive is satisfied.

On the contrary, the mobility motive and several other motives may be regarded as "positive" motives. It is possible to achieve a reward. If I drive fast, I will reach my target quicker. Driving fast may also give positive reinforcement regarding the pleasure motive, etc.

The conclusion is that a driver who feels that the safety motive is adequately satisfied will choose a driving style that, without jeopardizing his individually estimated personal safety, will give an immediate reward regarding as many other motives as possible, such as mobility, competition, self assertion etc. Most of these motives contradict safety but some of them, such as driving with high comfort, driving economi- cally or driving to save the environment, will as a secondary effect probably improve safety.

These types of phenomena have been studied and discussed by many researchers. Näätänen and Summala (1976) stress the importance of motivation for driving behaviour. They claim in their "zero risk theory" that drivers normally do not feel any risk when driving and thus the safety motive may be regarded as satisfied. Other motives, such as time reduction, competition, adventure seeking etc., the so called "extra motives", will make the driver drive faster and faster. Safety measures, such as improved cars, roads or driver, may fail to reach the goal of improved safety, since the driver will always tend to make use of the extra margins, not for increased safety, but for other motives, often resulting in higher speed.

Wilde $(1982,1989)$ suggests in his theory of risk homeostasis that the driver has a desired level of risk and that he continuously adjusts his behaviour to keep this level constant. The "perceived level of risk" is compared to this "target level of risk" and behaviour is adjusted to keep it in balance. In reaching this balance, there may still be margins for driving faster etc., thereby satisfying other motives as well.

In a study by Nilsson and Åberg (1990) it was shown that drivers' perceived probabilities correlated positively with corresponding objective probabilities of familiar situations, even when the objective probabilities were quite small, as in the risk of being involved in an accident or being detected by the police. This means that the feedback of accident involvement and detection is taken into consideration by the driver. Nilsson and Åberg also showed, however, that detection risk tends to influence driving behaviour more than accident risk.

Hale and Glendon (1987) point out that drivers involved in accidents without serious consequences may draw the same kind of conclusions, i.e. "It's not so dangerous after all". These mechanisms are often used to explain the lack of effects of different kinds of safety measures, such as driver improvement programmes (Struckman-Johnsson et al. 1989), driver training programmes (Schuster 1969; Utzelmann and Haas 1985; Drummond and Torpey 1985; Kadell 1987), motorcycle driver training (Simpson and Mayhew 1990), defensive driving courses (Lund and Williams 1985), skid training (Glad 1988), advanced driver training (Williams and O'Neill 1974), anti-lock brakes (Biel et al. 1991), voluntary children's safety club (Gregersen and Nolén 1994), road maintenance and zebra crossings. A general discussion of these aspects, including a review of the theoretical literature, is presented in the OECD report on "Behavioural adaptation" (OECD 1990). 


\section{SOCIAL INFLUENCE AND INDIVIDUAL PRECONDITIONS}

Part of the young drivers' problem concerns the fact that they are actually teenagers. Young people are in the middle of a process where they are about to liberate themselves from their parents etc. and assert themselves as grown-ups and independent individuals. This effort can be demonstrated in different lifestyles as well as in group affiliation, role expectations and varying degrees of social dependence. The importance of subjective norms in the driver's decision process has been described in the Fishbein and Ajzen theory of reasoned action (Ajzen and Fishbein 1980). Their point of view is in some respects related to the model in Fig. 1, but their model is focused on attitudes. Within general social psychology, there is a high level of knowledge concerning social development and interaction, but the research about its application on young drivers and their driving behaviour is very limited and highly focused on the problem of alcohol.

Marthiens and Schultze (1989) have described the importance of leisure activities for young driver accidents and overrepresentation of reports on "disco accidents". It was also found by Klemenjak and Hutter (1988) that two groups of teenagers visiting discos could be identified; the "disco fans", who spend the whole evening at the disco, and those who visit the disco spontaneously later in the evening. The second group is described as the most unsafe since they drive longer distances and their decision to go to the disco is more often taken after consumption of alcohol.

One example sometimes regarded as personality related and sometimes as part of the socialization process, is "adventure-seeking" or "sensation seeking". By using Zuckerman's "sensation seeking scale", Moe and Jensen (1990) have shown that there is a relation between sensation seeking and accident risk. The same kind of results were obtained by Beirness and Simpson (1991) in their comparison of a group of drivers involved in crashes and a group not involved. In their study, they also found an overrepresentation of smokers and drinkers, persons with less than 8 hours of sleep per night, persons with difficult relations with parents, teachers and other adults, and persons with other problem behaviour.

The relation between lifestyle and accident involvement has also been shown in a Swedish study (Gregersen and Berg 1994) and a German study (Schultze 1990). The Swedish study is a questionnaire study and shows that there are special high risk and low risk groups according to lifestyle. A typical feature of the highest risk group is that they seldom take part in any sports activities, they often drink alcohol and become intoxicated, they often drive for "extra motive" purposes and have a great interest in cars. They are often "out and about". The majority are men. The study defines a number of different lifestyle profiles that vary in accident involvement.

The German study of lifestyle and accidents, in which young drivers were interviewed, shows a similar pattern. Although the sample was too small to find any significant covariations with accident risk, there were tendencies pointing out the high risk groups "action type", "fan type" and "non-conforming type". The correspondence between the results from the two studies is relatively high. To some extent, these findings support the "problem behaviour theory" of Jessor and Jessor (1977) and the findings of Beirness and Simpson (1991) suggesting that risky driving covariates with other kinds of problem behaviour such as heavy drinking. However, the Swedish study also identified high risk groups which do not fit their model.

The Swedish study also suggests a relation between lifestyle and driving habits, i.e. time of day, driving purpose etc. This is also in line with the accident reducing effects of curfew systems for young drivers in different countries, mainly the U.S.A. (Preusser et al. 1984; Levy 1988; Williams et al. 1985).

\section{CONCLUSIONS}

The aim of this overview has been to present a structure of the specific problems of young novice drivers and to describe the state of the art in this area of research. The analysis of these driving behaviour factors shows that several dynamic and interactive processes are involved. It is also obvious that there are still several aspects that are not yet satisfactorily investigated and understood. There are varying degrees of knowledge about these factors and their interaction, and it is obvious that a great amount of work remains to be done. The research field of young drivers is still highly focused on one category of problems at a time, which makes it almost impossible to understand the relations between, for example, experience and driver training, experience and motivation, driver skill and risk compensation or lifestyle and driving style etc.

The model is primarily describing psychological, educational and social processes. It is, however, important to expand the field of research and also include aspects that are related to the young driver as a part of a system. How do young drivers make use of opportunities defined by the environmental preconditions of the road and the vehicle? How do they interpret and make use of traffic rules and how do they estimate risks and 
adjust their driving given certain combinations of car and road? In the model these aspects have only been indicated by the influence of "situation"-factors on driving behaviour. A closer analysis of the importance and content of these processes certainly needs to be carried out in future research.

Even if there are several gaps in knowledge, some of the factors have been well investigated. It may be concluded that experience is of greater importance than age-related factors, with the exception of the lowest driver ages of 15 years where age factors seem to be more important.

In our discussion, lack of experience as a problem has been interpreted as important for the level of mental workload. There are, however, other important aspects which need to be studied further. One example is the question of whether there is any difference, from a safety point of view, between the processes behind skill acquisition through formal teaching programmes and through long-term driving experience. Another question is how we can prevent novice drivers from adopting bad habits and bad informal rules in traffic, such as fast driving, red light infringements, neglecting to use the direction indicators etc., which are also the effects of experience. The novice driver's high mental workload may also result in other problems such as reduced possibilities of making use of the results of potentially good teaching methods and ideas. An important question is: is it possible to reduce at all the time needed to gain experience by using specially designed training strategies?

Obviously, feedback problems as discussed above are also the effects of experience. Rewarding feedback from erroneous behaviour and careless driving is obtained only through increased individual experience. On the other hand, however, analyses of accident statistics tell us that risks are reduced through experience, and therefore the positive effects must be larger than the negative. A valid conclusion may therefore be that we still have potentials for reducing accident involvement among young drivers.

These explanations of how knowledge, skill, experience and feedback related problems influence accident involvement also tell us something about measures. A lack of experience can be prevented by educational processes with increased experience and more effective strategies for learning to handle problems related to inadequate experience. Overestimation can be prevented through educational measures by making the drivers realize their own limitations. Other problems, however, such as the influence of subjective norms, lifestyle and personality do not directly tell us about measures, but rather help us to differentiate high risk drivers from low risk drivers. We gain knowledge about how to identify the high risk groups, but not about how to reduce their accident involvement.
Even if a driver is defined through his lifestyle, as a high risk driver it is probably not advisable to try to change his lifestyle. One reason is that we do not know the nature of the relation and whether it is causal or not. Even if we knew how to change lifestyles, we would not know what parts of the lifestyle to change and how much. The other reason is ethical. Lifestyle is a description of how we live our lives in a much broader sense than road safety alone. It is probably not advisable to try to change people's lifestyle solely from a road safety perspective, even if it were possible to define the pattern of causality. The consequences of such efforts on other aspects of life would be impossible to predict.

One potential strategy for improving safety among young drivers lies in early exclusion of dangerous drivers. This was also the purpose of earlier research in this area. Theoretically, factors such as personality, lifestyle, social background etc. may be used in such differentiating activities. By using our knowledge about how these factors covary with driving behaviour or accident involvement, risk-prone drivers could be identified. However, the state of the art in this respect is that not enough is known about these relations. We know that some personality factors and some lifestyle groups correlate with risk, but it is also obvious that these correlations are relatively weak and that available instruments suffer from low sensitivity as well as low specificity with respect to their ability to predict accident involvement. There is a high probability that high risk drivers will be missed and that low risk drivers will be excluded.

The question of exclusion is to a large extent political. In many countries, a driving licence is regarded as a necessity for transport needs and a citizen's right. However, it should not be forgotten that many countries already have a number of such exclusion criteria, such as medical health, criminal record and licensing tests. Many of these criteria for exclusion have been introduced on a common sense basis and have not been sufficiently investigated with respect to their specificity and sensitivity for accident proneness. We need more experimental and epidemiological research in order to utilize these results in terms of countermeasures.

Acknowledgements - This research was supported by grants from the Swedish Transport and Communication Research Board and the Swedish Road and Transport Research Institute.

\section{REFERENCES}

Ảberg, L. The human factor in game-vehicle accidents: A study of drivers' information acquisition. Acta Universitatis Upsaliensis, Studia Psychologica Upsaliensia 6. Uppsala: Dept of Psychology. University of Uppsala; 1981. 
Ahapalo, P.; Lehikonen, A.; Summala, H. Driving experience and response latencies. Report 12. Helsinki: University of Helsinki, Traffic Research Unit; 1987.

Ajzen, I.; Fishbein, M. Understanding attitudes and predicting social behaviour. Englewood Cliffs: Prentice-Hall; 1980.

Alm, H.; Nilsson, L. Changes in driver behaviour as a function of handsfree mobile telephones. VTI Reprint 175. Linköping: Swedish Road and Transport Research Institute; 1990.

Alm, H.; Nilsson, L. Effects of mobile telephone use on elderly drivers' behaviour-including comparisons to young drivers' behaviour. VTI Reprint 176. Linköping: Swedish Road and Transport Research Institute; 1991.

Anderson, J. R. Acquisition of cognitive skills. Psychol. Rev. 89:349-406; 1982

Beirness, P. J.; Simpson, H. M. Predicting young driver crash involvement: The role of lifestyle factors. International Symposium, New to the road, Prevention measures for young and novice drivers. Halifax; 1991.

Benda, H. V.; Hoyos, C. G. Estimating hazards in traffic situations. Accid. Anal. Prev. 15:1-9; 1983.

Biel, B.; Aschenbrenner, M.; Wurm, G. Einfluss der Risikokompensation auf die Wirkung von Verkehrssicherheitsmassnahmen am Beispiel ABS. Unfall und Sicherheitsforschung Strassenverkehr, Heft 1. Bergisch-Gladbach: BASt; 1991.

Brazell, R. E. A comparison of various Behind-the-wheels training methods. Lansing: The Safety and Traffic Division, Automobile Club of Michigan; 1962.

Brown, I. D.; Groeger, J. A.; Biehl, B. Is driver training contributing enough towards road safety? In Road users and traffic safety. Rothengatter, J. A.; de Bruin, R. A. (Eds). Assen: Van Gorcum; 1987.

Cooper, P. J.; Pinili, M.; Chen, W. An examination of the crash involvement rates of novice drivers aged 16 to 55 . Accid. Anal. Prev. 27:89-104; 1995.

Deutsch, D.; Sameth, S.; Akinyemi, J. Seat belt usage and risk-taking at two major traffic intersections. In: Proc of the 24th Conference of the American Association for Automotive Medicine. Arlington Heights; 1980.

Donovan, D. M.; Marlatt, G. A.; Salzberg, P. M. Drinking behaviour, personality factors and high risk driving. J. Stud. Alcohol 44:39-428; 1983.

Dreyer, D.; Janke, M. The effects of range versus nonrange driver training on the accident and conviction frequencies of young drivers. Accid. Anal. Prev. 11:179-198; 1979.

Drummond, A. E.; Torpey, S. E. Driver improvement program evaluation. Victoria: Road Traffic Authority; 1985.

Duncan, J.; Williams, P.; Brown, I. Components of driving skill; experience does not mean expertise. Ergonomics 34:919-937; 1991

Eriksson, R. Evaluation of education at driving ranges (in Swedish). Uppsala: University of Uppsala, Dept of Education; 1983.

Evans, L.; Wasielewsky, P. O.; von Buseck, C. R. Compulsory seat belt usage and driver risk taking behaviour. Human Factors 24:41-48; 1982.

Evans, L.; Wasielewsky, P. O. Risky driving related to driver and vehicle characteristics. Accid. Anal. Prev. 15:121-136; 1983.

Ferdun, G. S.; Peck, R. C.; Coppin, R. S. The teen-aged driver. An evaluation of age, experience, driving exposure and driver training as they relate to driving record. Highway Research Record, No. 163:3-53; 1967.

Fhaner, G.; Hane, M. Seat belts: Factors influencing their use. A literature survey. Accid. Anal. Prev. 5:27-43; 1973.

Finn, P.; Bragg, B. W. E. Perception of the risk of an accident by young and older drivers. Accid. Anal. Prev. 18:289-298; 1986

Fitts, P. M.; Posner, M. I. Human performance. Monterey, California: Brooks/Cole; 1962.

Fitts, P. M. Perceptual-motor skill learning. In: Categories of human learning. Melton, A. W. (Ed.). New York: Academic Press; 1964.

Forsythe, E. Cohort study of learner and novice drivers. Part 1: Learning to drive and performance in the driving test. Research Report 338. Crowthorne: Transport Research Laboratory; 1992.

Galin, D. Speeds on two-lane rural roads: A multiple regression analysis. Traffic Engng and Control, Aug-Sept:453-460; 1981.

Gaudry, M. Responsibility for accidents: Relevant results selected from the DRAG model. Publication 544. Montreal: Université de Montréal, Centre de recherche sur les transports; 1987.

Glad, A. Research on drinking and driving in Norway (in Norwegian). Temahefte 15, Samferdsel. Oslo: TÖI; 1985.

Glad, A. Phase 2 in driver education. Effects on accident risk (in Norwegian). TÖI rapport 15, Oslo: TÖI; 1988.

Gregersen, N. P. Evaluation plan for the 16-year age limit for practicing (in Swedish). VTI Notat 22. Linköping: Swedish Road and Transport Research Institute; 1991.

Gregersen, N. P. Integrated driver education. A trial with structured co-operation between driving schools and private teachers (in Swedish). VTI Rapport 376. Linköping: Swedish Road and Transport Research Institute; 1993.

Gregersen, N. P. Systematic co-operation between driving schools and parents in driver education, an experiment. Accid. Anal. Prev. 26:453-461; 1994.

Gregersen, N. P. Young drivers' overestimation of their own skill - an experiment on the relation between training strategy and skill. Accid. Anal. Prev. 28:243-250; 1996.

Gregersen, N. P.; Berg, H. Y. Lifestyle and accidents among young drivers. Accid. Anal. Prev. 26:297-303; 1994.

Gregersen, N. P.; Nolén, S. Children's road safety and the strategy of voluntary traffic safety clubs. Accid. Anal. Prev. 26:463-470; 1994.

Gregersen, N. P.; Brehmer, B.; Morén, B. Road safety improvement in large companies. An experimental comparison of different measures. Accid. Anal. Prev. 1996; In press.

Hale, A. R.; Glendon, A. I. Individual behaviour in the control of danger. Industrial safety series 2 . Amsterdam: Elsevier; 1987.

Harms, L. Variation in drivers' cognitive load. Effects of driving through village areas and rural junctions. Ergonomics 34:151-160; 1991a.

Harms, L. Studies of cognitive load in traffic: A summary presentation. VTI Reprint 177. Linköping: Swedish Road and Transport Research Institute; $1991 \mathrm{~b}$

Jessor, R.; Jessor, S. L. Problem behaviour and psychosocial development; A longitudinal study of youth. New York: Academic Press; 1977.

Jonah, B. A. Accident risk and driver risk-taking behaviour among young drivers. Accid. Anal. Prev. 18:255-271; 1986. 
Jones, M. H. California driver training evaluation study. Sacramento, CA: California State Department of Motor Vehicles; 1973.

Kadell, D. Traffic safety impact of the Home Instruction/Point Reduction Incentive Program. J. Safety Res. 18:149-178; 1987.

Klemenjak, W.; Hutter, M. Stellenwert des Discobesuches als Freizeitgestaltung und damit zuzammenhängende Verkehrssicherheitsprobleme. Wien: Verkehrpsychologisches Institut. Kuratorium für Verkehrssicherheit; 1988.

Koneci, C.; Ebbesen, E. B.; Koneci, D. K. Decision processes and risk-taking in traffic: driver response to the onset of yellow light. J. Appl. Psychol. 6:359-367; 1976.

Korteling, J. E. Effects of age and task integration on dual task performance. IZF 1990 B-11. Soesterberg: TNO Institute for Perception; 1990.

Korteling, J. E. Effects of aging and the development of automatic and controlled skills in driving. IZF 1992 B-6. Soesterberg: TNO Institute for Perception; 1992.

Lacko, P.; Nilsson, G. Seat belt usage in Sweden 1983-1986 (in Swedish). VTI Rapport 326, Linköping: Swedish Road and Transport Research Institute; 1988.

Lalonde, K. G. The grand record study of motor vehicle collisions in Ontario. Toronto, Ontario: Ontario Ministry of Transportation and Communications; 1979.

Lawson, J. J.; Arora, H. R. 1981 nighttime surveys of drivers' alcohol use. In: Proc of the 26th Conf. of the American Assoc. for Automotive Medicine. Arlington Heights; 1982

Levy, D. T. The effects of driving age, driver education and curfew laws on traffic fatalities of 15-17 year olds. Risk Analysis 8:569-574; 1988

Levy, D. T. Youth and traffic safety: the effect of driving age, experience, and education. Accid. Anal. Prev. 22:327-334; 1990.

Lund, A. K.; Williams, A. F. A review of the literature evaluating the Defensive Driving Course. Accid. Anal. Prev. 17:449-460; 1985.

Marek, J.; Sten, T. Traffic environment and the driver. Driver behaviour and training in international perspective. Springfield: Charles C. Thomas; 1977.

Marthiens, W.; Schultze, H. Analyse nächtlicher Freizeitunfälle junger Fahrer. In: Disco-Unfälle-Fakten und Lösungsstrategien. Bergisch-Gladbach: BASt; 1989.

Matsui, J.; Clarke, H.; Clifford, L.; Duncan, D. Survey of road user knowledge. SCDO 91-117. Ontario: Safety and Co-ordination \& Development Office; 1991.

Matthews, M. L.; Moran, A. R. Age differences in male drivers' perception of accident risk: The role of perceived driving ability. Accid. Anal. Prev. 18:299-314; 1986.

Maycock, G.; Lockwood, C. R.; Lester, J. F. The accident liability of car drivers. TRL Research Report 315. Crowthorne: Transport Research Laboratory; 1991.

Mayhew, D. R.; Donelson, A. C.; Beirness, D. J.; Simpson, H. M. Youth, alcohol and relative risk of crash involvement. Accid. Anal. Prev. 18:299-314; 1986.

McGormick, I. A.; Walkey, F. H.; Green, D. E. Comparative perceptions of driver ability - a confirmation and expansion. Accid. Anal. Prev. 18:205-208; 1986.

McKenna, F. P. It won't happen to me: unrealistic optimism or illusion of control? Br. J. Psychol. 84:51-65; 1993.

McKenna, F. P.; Stanier, R. A.; Lewis, C. Factors underlying illusory self-assessment of driving skill in males and females. Accid. Anal. Prev. 23:45-52; 1991.

Michels, W.; Schneider, P. A. Traffic offences: another description and prediction. Accid. Anal. Prev. 16:223-238; 1984

Miltenburg, P. G. M.; Kuiken, M. J. The effect of driving experience on visual search strategies: Results of a laboratory experiment. Report VK-90-24. Haren: Rijksuniversiteit Groningen; 1990.

Moe, D. Driver education class B for 16 year old youngsters (in Norwegian). SINTEF Rapport STF63 A92002. Trondheim: SINTEF Samferselsteknikk; 1992.

Moe, D. Young drivers. Relation between perceived and real ability. Behaviour studies (in Norwegian). TFBrapport 1986:17. Stockholm: Swedish Transport and Communication Research Board; 1986.

Moe, D. Young drivers. Relation between perceived and real ability (in Norwegian). TFD Report 1984:5. Stockholm: Swedish Transport and Communication Research Board; 1984.

Moe, D.; Jensen, G. D. Young drivers, risk taking and educational consequences (in Norwegian). SINTEF Report STF63 A90007. Trondheim: SINTEF Samferdselsteknikk; 1990.

Mourant, R. R.; Rockwell, T. H. Strategies of visual search by novice and experienced drivers. Human Factors $14: 325-335 ; 1972$.

Mourant, R. R.; Grimson, C. G. Predictive head-movements during automobile mirror sampling. Perceptual and Motor Skills 44:238-286; 1977.

Nilsson, R.; Åberg, L. Unusual traffic experiences. Different measures of the perception of small probabilities (in Swedish). TFB Meddelande 169. Stockholm: Swedish Transport and Communication Research Board; 1990.

Nolén, S. Is there any relation between the driver's experience, attitudes and beliefs and his/her use of seat belts? VTI Rapport 338. Linköping: Swedish Road and Transport Research Institute; 1988.

Näätänen, R.; Summala, H. Road user behaviour and traffic accidents. Amsterdam and New York: North Holland/ American Elsevier; 1976.

OECD. Behavioural adaptations to changes in the road transport system. Paris: OECD; 1990.

Pelz, D. C.; Schuman, S. H. Are young drivers really more dangerous after controlling for exposure and experience? J. Safety Res. 3:68-79; 1971 .

Potvin, L.; Champagne, F.; Laberge-Nadeau, C. Mandatory driver training and road safety: The Quebec experience. Am. J. Public Health 78:1206-1209; 1988

Preusser, D. F.; Williams, A. F.; Zador, P. L.; Blomberg, R. D. The effect of curfew laws on motor vehicle crashes. Law and Policy 6:115-128; 1984.

Quimby, A. R.; Watts, G. R. Human factor and driving performance. LR 1004. Crowthorne: Transport Research Laboratory; 1981.

Rasmussen, J. Information processing and human-machine interaction. An approach to cognitive engineering. New York: North-Holland; 1984.

Schulze, H. Lifestyle, leisurestyle and traffic behaviour of young drivers. In: VTI Report 364A. Linköping: Swedish Road and Transport Research Institute; 1990.

Schuster, D. C. Follow-up evaluation of the performance of driver improvement classes for problem drivers. J. Safety Res. 1:80-87; 1969.

Shaoul, J. The use of accidents and traffic offences as criteria for evaluating courses in driving education. Salford: University of Salford, Department of Civil Engineering, Road Safety Research Unit; 1975.

Simpson, H. M.; Mayhew, D. R. The promotion of motor- 
cycle safety: training, education, and awareness. Health Educ. Res. 5:257-264; 1990.

Skelly, G. B. Aspects of driving experience in the first year as a qualified driver. LR 149, Crowthorne: Transport Research Laboratory; 1968.

Smith, M. F. Research agenda for an improved novice driver education program. Report to the Congress. NHTSA Report DOT HS 808 161. Washington, DC: National Highway Traffic Safety Administration: 1994.

Soliday, S. M.; Allen, J. A. Hazard perception in automobile drivers; Age differences. Highway Research Center. University of North Carolina; 1972.

Spolander, K. Accident risks of drivers. A model tested on men and women (in Swedish). VTI Rapport 268. Linköping: Swedish Road and Transport Research Institute; 1983a.

Spolander, K. Driver's assessment of their own driving ability (in Swedish). VTI Rapport 252, Linköping: Swedish Road and Transport Research Institute; $1983 \mathrm{~b}$.

Stock, J. R.; Weaver, J. K.; Ray, H. W.; Brink, J. R.; Sadof, M. G. Evaluation of Safe Performance Secondary School Driver Education Curriculum Demonstration Project. Columbus, Ohio: Battelle Columbus Laboratories; 1984.

Strang, P. M.; Deutsch, K. B.; James, R. S.; Manders, S. M. A comparison of on-road and off-road driver training. Report 1. Canberra: Road Safety and Traffic Authority; 1982.

Struckman-Johnson, D. L.; Lund, A. K.; Williams, A. F.; Osborne, D. W. Comparative effects of driver improvement programs on crashes and violations. Accid. Anal. Prev. 21:203-215; 1989.
Svenson, O. Are we all less risky and more skillful than our fellow drivers? Acta Psychol. 47:143-148; 1981.

Swedish National Road Administration. Unpublished statistics from the Swedish Licence Register.

Utzelmann, H.; Haas, R. Evaluation der Kurse für Mehrfach auffällige Kraftfahrer. Heft 53. Bergisch-Gladbach: BASt, Unfall und Sicherheitsforschung, Strassenverkehr; 1985.

Wasielewsky, P. Speed as a measure of driver risk: observed speeds versus driver and vehicle characteristics. Accid. Anal. Prev. 16:89-104; 1984.

Wickens, C. D. Processing resources and attention. In: Multiple task performance. Damos, D. L. (Ed.). London: Taylor \& Francis; 1991.

Wilde, G. J. S. The theory of risk homeostasis: Implications for safety and health. Risk Analysis 2:209-258; 1982.

Wilde, G. J. S. Risk homeostasis theory and its promise for improved safety. In: Riskhomeostasis? VTT symposium 124, (NOFS 89) Nurmes. Finland: VTT; 1989.

Williams, A. F.; O'Neill, B. On-the-road driving record of licensed race drivers. Accid. Anal. Prev. 6:263-270; 1974.

Williams, A. F.; Lund, A. K.; Preusser, D. F. Night driving curfews in New York and Louisiana: Results of a questionnaire survey. Accid. Anal. Prev. 17:461-466; 1985.

Wilson, R. J. A national household survey on drinking and driving: knowledge, attitudes and behaviour of Canadian drivers. TMRU 8402. Road Safety Directorate, Transport Canada; 1984.

Wilson, R. J.; Jonah, B. A. Identifying impaired drivers among the general driving population. J. Stud. Alcohol 46:531; 1985. 



\section{a}

Swedish National Road and
Transport Research Institute

RESEARCH FOR MOBILITY

The Swedish Road and Transport Research Institute has laboratories and know-how for advanced research commissions in transport and welfare economics, road safety, vehicles and the environment. It also has research capabilities for the construction, operation and maintenance of roads and railways. 